\title{
EXPLORING PROFESSIONAL BOUNDARIES: A SHIFT TO INTER-PROFESSIONAL EARLY CHILDHOOD INTERVENTION PRACTICE IN LITHUANIA
}

\author{
Stefanija Ališauskienė \\ Šiauliai University, Lithuania \\ Violeta Gevorgianienè \\ Vilnius University, Lithuania
}

\begin{abstract}
A vast body of literature is focusing on the interdisciplinary approach in the field of early childhood intervention (ECI) practice, however inter-professional relations challenge traditional understanding of professional role and identity. The article contributes to the discussion about the value and the pitfalls of inter-professional cooperation in the field of ECI and its possible effects on family and child life. The aim of the research was to explore what competences professionals representing different fields perceive as most important for successful inter-professional collaboration. The study was based on experts' evaluation (questionnaire). An analysis of the data revealed the importance professionals allocated to opinion-sharing in the emerging early childhood intervention inter-professional teams as well as a lack of attention to the parents' voice, which indicates the need for further cohesiveness - a shift from a polylogue of different disciplines to an inter-professional culture.
\end{abstract}

Keywords: early childhood intervention, inter-professional relationships, parents, professional boundaries, shared competence.

\section{Introduction}

A vast body of literature (Peterander, 2003a, 2003b; Pizur-Barnekow et al., 2011) is focusing on the interdisciplinary approach in the field of early childhood intervention (ECI) practice. There is little doubt that any person or family in a difficult personal, professional or social situation benefits best from the support of a team of professionals (Peterander, 2003a; Inkilä et al., 2013). Professional role boundaries in some professional fields (e.g. health) have always been dynamic, though exhortation towards new inter-professional roles and cultures is more recent and global ${ }^{1}$. There is significant evidence, that interprofessional relationships and learning from each other does produce positive outcomes for the participants in terms of changing attitudes towards another profession, increasing knowledge of inter-professional cooperation and enhancing collaborative behaviour (Reeves et al., 2010).

A prominent strand of this research has been the study of professional identity and inter-professional relationships. It is admitted, that the competence of inter-professional cooperation presupposes constant communication, the

\footnotetext{
${ }^{l}$ www.srhe.ac.uk/conference2012/abstracts/0094.pdf
} 
ability to transfer professional information in such a way that it is understandable and meaningful to others (Thompson, 2013; Freeman \& Vakil, 2004). It also implies the attitude to learn - that is, to reflect and challenge one's own professional information and to review the gist of the work or professional paradigm (Mitchel et al., 2010). From an epistemological perspective, knowledge is not a fixed or unquestionable end product, but is negotiable and constructed through cooperation (Ampartzaki et al., 2013).

The international debate on professional identity and inter-professional relationships has, however, not fully considered how challenging the overcoming of traditional professional boundaries can be in the new type of inter-disciplinary practices in a specific socio-cultural context (e.g. in postsoviet Lithuania). In this context we aimed to analyse how professionals from different fields working in the field of ECI see and interpret their professional collaboration through the expression of the expected competencies and those observed in real situations of inter-disciplinary teamwork. The exploratory study, including analysis of experts' training portfolios and questionnaires, has been used as a method of the research. Using exploratory research we as researchers sought to understand better the interprofessional collaboration in the field of ECI. An exploratory research was an attempt to determine if the results might be explained by a currently existing theory. For the analysis of professional roles and competencies needed in ECI the constructivist approach, namely Bourdieu's conception, has been employed. In doing so, it is envisaged that a stronger awareness of inter-professional relationships could lead to improved professional dialogue, as well as the promotion of new forms of partnerships and a new focus in the development of inter-disciplinary training programmes.

The research presented in this article has been implemented in two stages: first stage of the research aimed at the analysis of a training content of different professionals and was undertaken in 2011; the second stage aimed to explore how ECI professionals interpret their professional roles in teamwork through an articulation of the assumed and observed in reality competencies. The second stage was undertaken from September, 2012 to March, 2013.

Ethical considerations. The participants were informed about the research aims, methods and the use of the results before the research started. Confidentiality of their personalities was assured. In order to respect the privacy and autonomy of the specialists only those who were willing to took part in the research.

\section{The development of early childhood intervention in Lithuania}

In Lithuania, the system of early childhood intervention/ ECI for very young children (0-3) in need and their families started to be established in 1996. This system supplemented the educational support for children aged from 3 to 7 
and employed the approach of disability prevention. The services of ECI are organised according to the teamwork principle. In general, the ECI system in Lithuania is mostly focused on therapy given to the child (Ališauskienè, 2010). In recent decades the prevailing traditional child-centred and therapy-based orientation is shifting from a deficit model, focused on the child's disorder, to a social model, orientated towards the systemic support for a child and a family, positive development of the parents/ child relationship, the involvement of parents in the process of intervention and the creation of links between the family and community (Ališauskienè, 2005). Based on the new documents from 2011, and new initiatives the focus in ECI has shifted from the child to a child in his/her family as a system, and to a wider context. The focus on the ecology of the child and family has challenged the traditional roles of professionals. Professionals of different fields/ agencies need to learn to work together and develop a shared team competence: to cooperate in formulating aims, tasks and intervention procedures, and to cooperatively evaluate the outcomes of the intervention. The inter-agency and multi-disciplinary cooperation did take place in ECI services a couple of decades ago, but not on a regular basis and it depended more on a voluntary initiative and not on the inter-professional paradigm.

Reflecting on the past experiences, it is evident that the role of a professional was strictly defined by the precise set of functions described in a certain professional code and did not foresee inter-disciplinary cooperation nor flexibility in professional roles and functions. The emphasis on professional identity was strengthened by the historically developed "niche" of certain professions and their status and prestige in society. In this aspect the discussion can be based on P. Bourdieu's conception of habitus, capital (knowledge, linguistic, cultural, etc.), "practical theory", which emphasizes virtuous interactions between individuals (King, 2000). Bourdieu's practical theory offers a way out of the impasse of objectivism and subjectivism by focussing on the inter-subjective interactions between individuals (ibid). According to Bourdieu, "the habitus, the product of history, produces individual and collective practices, and hence history, in accordance with the schemes, engendered by history" (Bourdieu, "Outline of a theory of practice", 1977, p. 82). The concept of habitus implies that "all meaning is socially constructed and culturally arbitrary" (McKnight, 2012, p. 83), which also means that habitus implies power and privilege as well as the reproduction of existing relationships and / or structures. Carpenter \& Phil (1997) refer to tensions that arise when professionals mediate their identities as professionals, increasingly as members of integrated service teams. The inter-disciplinary cooperation in ECI might be problematic, when professionals encounter a variety of complex new roles in multi-service settings.

Apart from the philosophical framework of Bourdieu the arguments of Anning et al. (2006); Osgood (2012) (in Payler \& Georgeson, 2013) about the historically developed social status and power of a certain profession, deeply 
rooted cultural differences and lack of trust between professional groups (Watkin et al., 2009) is also fully applicable in Lithuania.It is a country with a short history of inter-disciplinary teamwork in ECI, but a long history of fundamental and prestigious disciplines such as medicine, and later psychology. The legislative documents related to professional requirements for specialists of different fields working in multi-service settings (e.g. ECI centres) show that the competence of cooperation is mostly stressed in the requirements for professionals of social fields (social pedagogues, psychologists, etc.), but not in those of medicine. However, professionals from different fields are part of the newly developed multi-professional ECI teams and their participation might have influence on the characteristics of inter-professional relationships and cooperation.

\section{Individual professional competencies vs mutually shared team competence}

ECI professionals working in teams come from different professional fields and provide support to vulnerable persons, e. g. young children with developmental difficulties and their families. The requirements for professional competence in this area are very high - professionals need specific knowledge and skills, an inter-disciplinary approach and have to be able to create supportive and empowering culture in the organization. Team building approaches require shared principles, objectives and working strategies, that is, shared competencies, necessary for ECI. Moreover, in order to communicate, team members need to develop common meanings and use a common language. This allows for a common knowledge creation (cognitive factors) determining the mutually shared conception of the team (Bossche et al., 2006). Along with the cognitive competence, technical (skills) affective competency (attitudes) is also needed in order for teamwork to be effective (Sargeant et al., 2008). It is also true, that the collaborative culture in ECI is influenced by interpersonal relationships among the team members (social factors) (Bossche et al., 2006). The collaborative culture ensures cooperation not only among professionals, as the experts of theoretical knowledge, but between them and the parents, as the experts in the everyday life of their child, whose children need support.

A collaboration culture is based on communities of practice - groups of people who share a concern or a passion for something they do and learn from each other how to do it better as they interact regularly and have an opportunity to develop personally and professionally (Lave \& Wenger, 1998). The contemporary paradigm of the ECI stresses the importance of communities of practice, though the phenomenon is still not very much discussed in Lithuania. Communities of practice have a distinct identity that is defined by the rules of their professional practice (Ampartzaki et al., 2013, cit. Wenger et al., 2002). Under the circumstances when a community of practice consists of professionals from different fields the cooperation within or amongst such communities 
involves the problem of professional boundaries and their flexibility. As a specialist one has to not only be aware of one's professional competence but also be able to cross professional boundaries in order to learn - that is, to challenge one's own professional identity, and thus the creation of a new habitus as a set of shared values, traditions and skills occurs. This process is called interprofessional learning and can be described as learning "...with, from and about each other in order to improve collaboration and the quality of care..." (Watkin et al., 2009, p. 152).

The factor of professional status plays an important role not only on a macro level (in terms of the profession's status in society), but also on a micro level of decision making. Often a "full picture", consisting of various professional insights is determined by the leader of the service, by the person who provides a direct service to the child or the expert who consults the provider of the direct service (Freeman \& Vakil, 2004; Thompson, 2013). However the term "expertise" in the context of multi-disciplinary cooperation may be destructive if used to name an individual professional, because, according to Bourdieu, it can conceal the "symbolic violence", which implies the imposition of a certain paradigm by the subject with the power. The relevant attitude therefore would be to speak about a shared capacity or expertise of a team and a shared power (Freeman \& Vakil, 2004; Payler \& Georgeson, 2013).

In this context it was also important to discuss the role of the family, which was one of the aims of our research.There is a lot of evidence, that family involvement is a significant factor in achieving success in ECI (Carpenter \& Phil, 1997; Guralnick, 2001; Peterander, 2003a, 2003b; Ališauskienè, 2005), but many professionals still adhere to the old fashioned paradigm which preferences professional expertise (Block \& Block, 2002). Parents' participation in decision making might create an uneasiness among staff, when the meaning and nature of parental involvement lacks clarity. It is not easy to find the balance of power in parent-professional relationships (Shimoni \& Ferguson, 1992; Carpenter \& Phil, 1997). Reflecting on Bourdieu, parents are the ones who intervene in the interchange of professional habitus, and unwillingly complicate their discourse. Along with that (and because of that) the work with the family presupposes the ability to be open-minded and flexible, because of the unpredictable, changing, and "fleeting reality" of family life (Thompson, 2013).

\section{Training content of professionals working in ECI: findings from the first stage of the research}

\section{Research design}

In order to identify competencies which professionals of various fields gain formally and informally in their professional studies the content of professional training portfolios $(\mathrm{N}=60)$ of specialists working in the field of ECI were assessed with regard to the recommendations of the European program 
$(\mathrm{EBIFF})^{2}$. Descriptive statistics based on a secondary document analysis were applied with the aim of identifying which knowledge/skill areas dominate in the content of each discipline's professional training and what areas of different professional's training are specific and/or common.

Sixty professionals working in the field of ECI in Lithuania participated in this research stage. The research sample consisted of representatives from different sectors and professionals (providing special educational support: 20 speech therapists, 6 special teachers, 11 physiotherapists; health care professionals: 3 paediatricians, 2 nurses; also, 5 social field professionals; 9 preschool teachers; 4 psychologists) who work in the field of ECI. All participants were females.

\section{Results}

The data analysis revealed that the content of professional training is geared towards the sphere in which they operate and is directly connected with their occupation and its specific functions. The dominant areas in addition to those that are in the content of different professionals' training portfolios ${ }^{3}$ have been identified (see Figure 1).

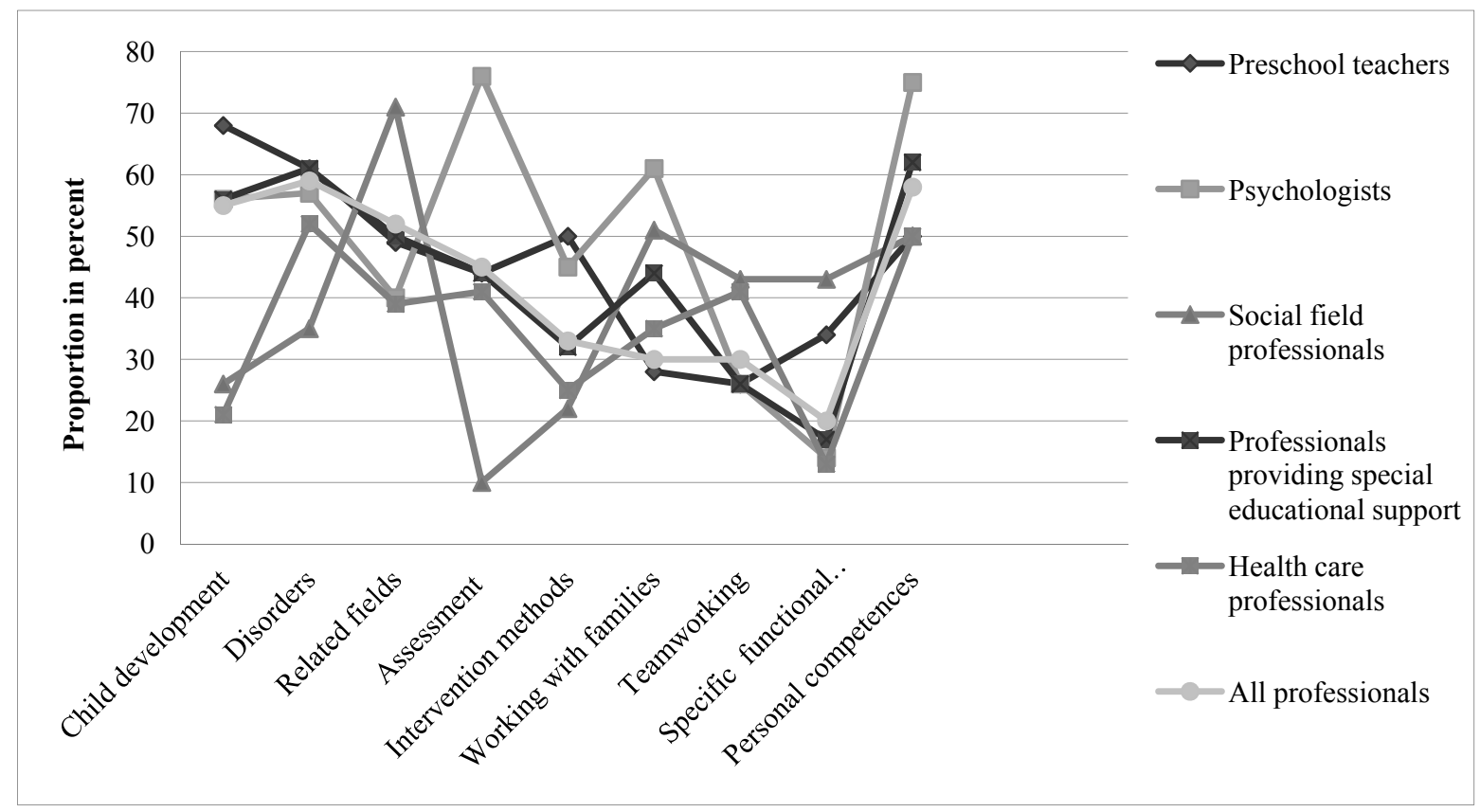

Figure 1. Training content of professionals working in the field of ECI

\footnotetext{
2 EBIFF / Curriculum for the professional training in Early Childhood Intervention, 2006. More information:www.ebiff.org

${ }^{3}$ Professional Training Portfolio is used to store one's career and employment history, qualification and training certificates and any other documentation relating to the professional development (see $\mathrm{http} / / / \mathrm{www}$.surreycc.gov.uk/learning/early-years-and-childcare-service/early-years-practitioners-andproviders/your-professional-development-in-early-years/professional-development-portfolio-for-early-years,playwork-and-childcare-practitioners).
} 
The dominating competence areas of preschool educators and professionals providing special educational support are child development, various disorders, intervention methods and knowledge from related fields (disciplines). Portfolios of psychologists working in ECI revealed the following dominating content: ability to assess child's development, to work with families and personal competencies, including good communication skills. The training content of pediatricians and nurses is focused on knowledge of disorders and related fields. Analysis of social field professional portfolios shows that their training focuses on working with families and specific professional functions ${ }^{4}$. Comparing the portfolios of these professional fields certain discrepancies in knowledge and/or competencies that may hinder inter-professional collaboration became evident. One of the fields that informs about possible misunderstandings is in the area of child development: $68 \%$ of preschool teachers comparing with $21 \%$ of health care professionals and $26 \%$ of social field professionals had the opportunity to gain knowledge in this field. Another large knowledge gap is manifested in the assessment area. Most competent in this field, according to the data analysis, are psychologists (78\%), least are those in the social field professionals $(10 \%)$. Work with families is the most important issue in early childhood intervention (Shimoni \& Ferguson, 1992; Carpenter \& Phil, 1997), though it is evident that health care professionals (35\%) and preschool teachers (28\%) had fewer possibilities to learn to cooperate with parents compared to psychologists $(61 \%)$ or social field $(51 \%)$ professionals.

In general, according to the findings, the training of all professionals working in the field is mostly oriented to their specific discipline (this is evident in the content of formal training at Bachelor / Master level, as well as in informal and in-service training). The knowledge and competencies acquired by professionals focus on problem identification (different disorders $-59 \%$, child's development $-55 \%$, assessment $-45 \%$ ) as well as related areas $-52 \%$. However, there is a lack of discipline necessary to successfully select and apply ECI models (including philosophy, approaches, methods - only $33 \%$ ). There is also a lack of evidence proving the preparedness of those professionals to understand the child's development and its assessment. In all professional portfolios we found evidence of certain knowledge in teamwork $(30 \%)$ and work with the family $(30 \%)$, but at the same time there is a lack of general competences, independent of the profession and important for ECI practice (such as the ability to cooperate with other professionals and families) as well as specific functional competencies (20\%), which are extremely important for inter-disciplinary practice in the field of ECI.

The findings revealed considerable differences in knowledge and skills which specialists gain during professional studies. The results motivated authors

\footnotetext{
${ }^{4}$ Due to the function in ECI, due to the target groups, due to institutional requirements, due to legal framework (see EBIFF).
} 
to study further how specialists working in inter-professional areas, such as ECI, perceive competences which are important for the inter-professional team work.

\section{Inter-professional cooperation in ECI: findings from the second stage of the research}

\section{Research design}

The second research stage was based on experts' evaluation (questionnaire), assuming that specialists working in inter-professional teams can be viewed as experts of inter-professional cooperation. It is also often referred to as practitioner based research and refers to a practical way of looking at one's own work to check if it is as one would like it to be (McNiff, 2002). The research took place during seminars for professionals working in the field of ECI in different regions of Lithuania. Despite the main purpose of the seminars to disseminate new ideas related to a shift of paradigm, we had an intention to improve our understanding of ECI practice (especially, to better understand what competences team members emphasise as most important) as well as to create a learning environment which would allow participants to engage in shared activities, help each other, share information and to build relationships that would enable them to learn from each other. The seminars (10 seminars of two days each) were based on U. Bronfenbrenner's ecological approach, which is successfully applied in ECI (Peterander, 2003a, b; Guralnic, 2001; Alisauskiene et al., 2007).

183 participants completed the answers to 2 open-ended questions: What competences you stress (expect) as most important for successful teamwork in the field of early childhood intervention? What competences you recognise as successfully implemented by your colleagues? Participants returned 1054 responses (further - propositions) to the first question and 532 to the second. The extended discussions in Focus groups based on the answers and reflections of participants, were organised at the end of each seminar. Initial open coding was conducted based on principles of content analysis of the written answers: the propositions were categorized according to their themes. In this process no categories were invented $a$ priori (Elo \& Kyngäs, 2007). The number of propositions in each category and ratio of each within all propositions was counted in the second stage of analysis. In the third stage of the data analysis competencies related to the category of team work were subdivided into smaller sub-categories. The validation of the results was performed by participants and three external experts (all experts have $\mathrm{PhD}$ in social sciences and teamwork experience in multi-professional practice). The study was based on descriptive statistics.

Research participants. The research sample was composed of 183 professionals working in the field of ECI in Lithuanian early rehabilitation services, pedagogical psychological services, kindergartens, and children rights' 
protection service. The participants were from the following fields:speech therapists (38), physiotherapists (13), special pedagogues (50, including 7 teachers for children with visual impairment, and 11 teachers for children with hearing impairment), psychologists (38), paediatricians (6), pre-school teachers (23), social pedagogues / workers (15). Participants represented all the country (55 areas) and 75 services: 32 pedagogical psychological services from $54(60 \%$ of all services); 19 early intervention services from 38 (50\%); 23 pre-school institutions and 1 children's rights service. The demographic profile of the group is almost homogeneous in terms of gender (only 1 male from 183 participants took part) and the average number of years of service as an ECI professional was 10 years. All participants have Bachelor's or Master's degree. Along with professionals, representatives of families (1-2 parents in each seminar) took part in the training.

\section{Results}

In analyzing the data, first, it became evident that there was a sharp contrast between the number of competencies the participants could name in their speculative thinking (when participants formulated their expected competencies - 1054 propositions) and in the reflection of practice, when they had to recall the valuable competencies they observed in their team work (532 propositions).

Competences which participants identified as most important for the successful team work in speculative thinking were grouped under the following titles: a) team competences $(29.5 \%)$, b) individual professional competencies $(26.3 \%), 3)$ personal competences (for instance sincerity, creativity, etc.) 23.2\%. Competences observed in real situations of inter-disciplinary teamwork practice and stated by EIC members as the most significant and most visible ones were divided as follows: personal competencies $-39.7 \%$, b) team competences $(22.3 \%)$, c) individual professional competencies $(15.2 \%)$. It is evident, that internal differences within each category are not considerable, however, the number of referrals to personal competence which are observed in real practice is salient (Figure 2 ).

Many answers had to be summarized under the category of "tautology" (the use of redundant words), because the wording of those propositions just repeated the wording of the question: to the question what competencies do you need to work successfully as a team some participants answered: to work as a team (6.2\% in theoretical and $5.7 \%$ in practice reflection).

In speculative thinking just few participants mentioned collaboration with parents (1.8\%): $7.5 \%$ of them, had, however, observed the value of parents' input for the EIC team work in practice. Other propositions, after analysis, were included in the category "basic communication skills". These were mostly composed of the capability to speak clearly and to listen to others. 


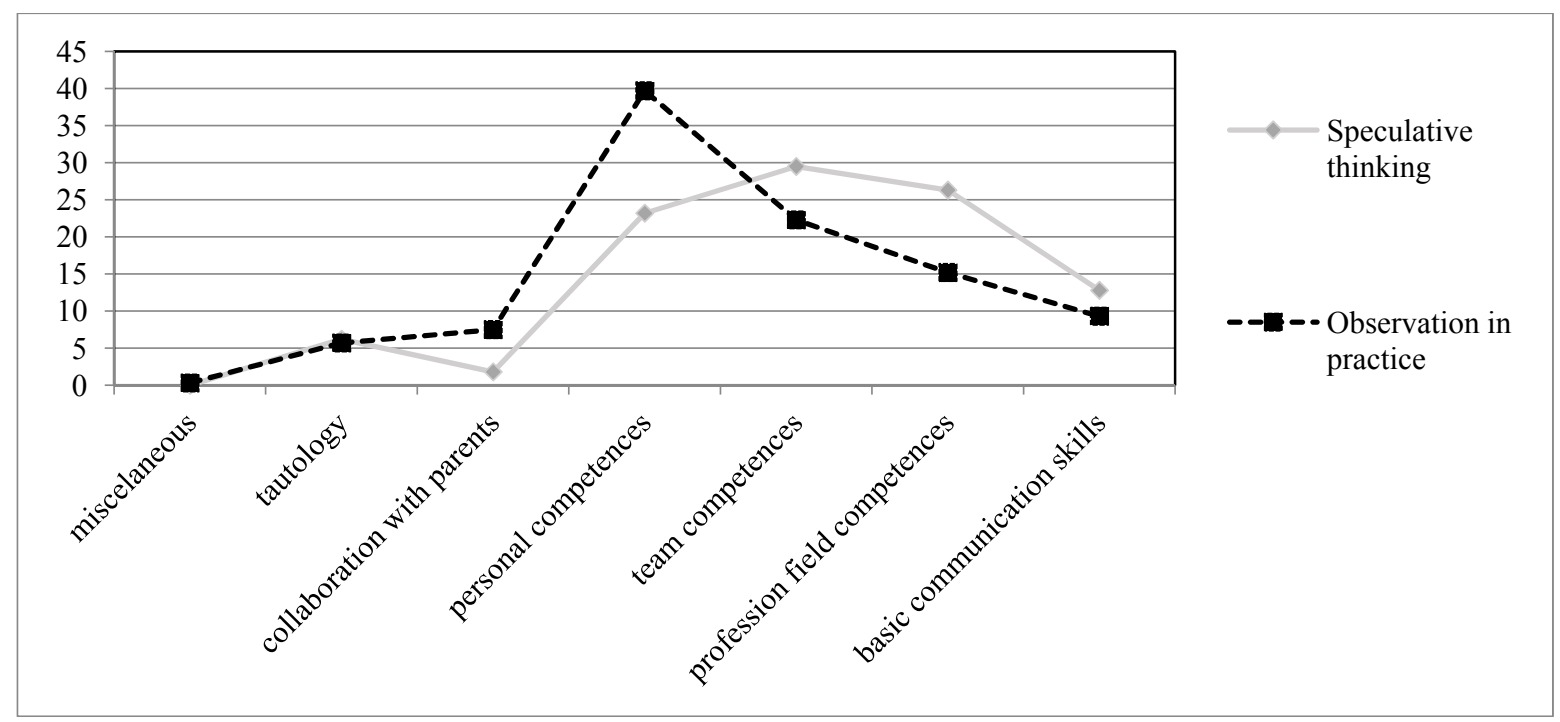

Figure 2. Structure of the competencies important for successful team work

As it was said in the methodology, in the next stage of the content analysis propositions in the category "team competence" were further analyzed in order to identify a structure of the category and frequency of the statements (Figure 3). In the category of team work two subgroups could be distinguished: 1) disposition to work in a team $(23.6 \%$ of statements in speculative, $13 \%$ in practice reflection), 2) instrumental team competencies (76.4\% and $87 \%$ accordingly). The highest number of propositions, both in speculative thinking and in practice observation, revealed the importance which participants allocated to the ability to express and substantiate one's opinion in professional discussion (26.9\% and $35.2 \%$ accordingly). The other important areas in speculative thinking were: tolerance and respect (14.2\%), capability to accept the other's opinion (13.5\%), ability to coordinate actions (11.2\%).

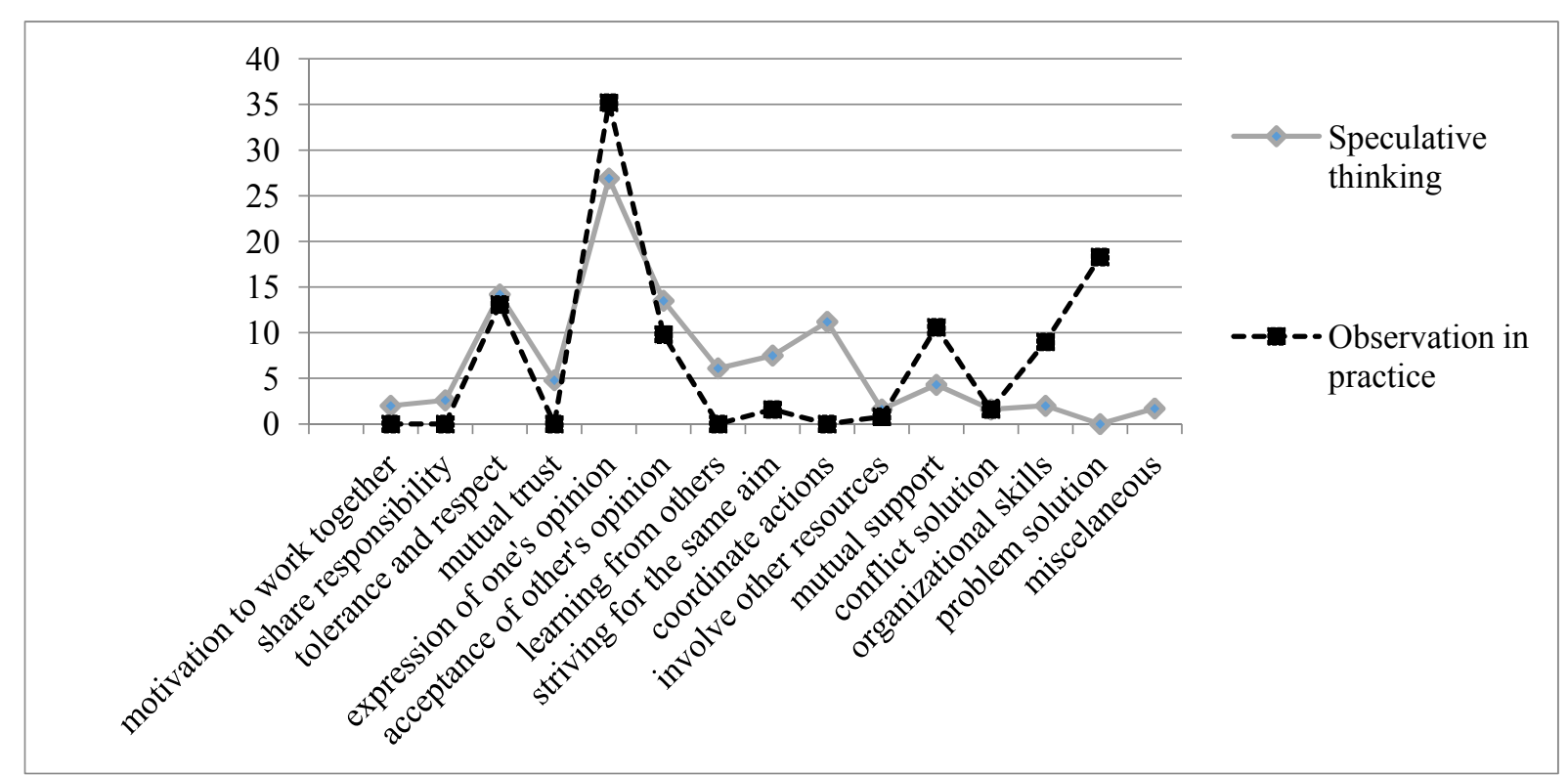

Figure 3. Structure of the team competence 
In the analysis of propositions related to a real practice a new category has emerged, which was absent in the speculative thinking: this was the ability to solve problems $(18.3 \%)$. The other competencies, frequently mentioned by the participants reflecting their practical observations fell into the categories tolerance and respect $(13.1 \%)$, mutual support (10.6\%), ability to accept the other's opinion $(9.8 \%$ ) and organizational skills (ability to manage time, and to guide the group in discussion, etc. $-9 \%$ ).

In general, skills observed by early childhood intervention specialists in their daily practice are more concentrated in their content than the ones they formulated based on their speculative thinking. These main team competences could be summarized as follows: in practice, specialists of ECI appreciate the ability of colleagues to clearly express and value their opinion in solving different professional problems, a readiness to accept other views and do it in the atmosphere of tolerance, respect and mutual support in the team work. After a secondary analysis some statements included in the category "personal competencies" were distinguished separately due to their negative formulation: not to be afraid to express one's opinion, not to be afraid to make a mistake, not to be superior towards the other, not to perceive comments as a criticism, not to remind others of their mistakes, not to use a "teaching intonation", etc. Such formulations were found in $10 \%$ of questionnaires.

In some questionnaires the use of specific terms and statement of very specific skills, mostly related to a medical model and to other professional fields was evident. For instance: ability to talk with a patient, knowledge in medical psychology, ability to design language development program, etc. Such specific statements were found only in $3 \%$ of questionnaires, but the content of those questionnaires in general was concentrated mostly on the individual professional field and had little to do with team work.

\section{Discussion}

The intensity of expectations for the competencies that are important for successful ECI team work are very similar for three categories - team, individual professional and personal competencies, with a slightly higher emphasis on the team, however this could be affected by the question itself. In response to the question "what do you think is important..?" respondents articulate their own knowledge of the topic, team work in this case. In the reality of daily practice, personal competencies (sincerity, humor, kindness, etc.) overrun the other two dominating categories which suggest the importance of a general feeling of compatibility in team work. Adopting Bourdieu's term these personal competencies might be referred to as social capital, which in the situation of the inter-professional encounter (and, thus, the contest of the habitus) play the role of a "damper" or a "shock absorber", helping the professionals to accept flexible professional boundaries. In his reflection on 
Bourdieu, Frank (2012) states, "capital and habitus - intimately related as they are create terms of recognition between persons" (p. 328).

The inter-professional collaboration in ECI services is further illustrated by the group of answers initiated with "not to..." Such propositions supposedly manifest certain insecurity in the team and stress the need for a good psychological climate. Therefore, it is no surprise, that an important role in our data was attributed to such preconditions of common work as tolerance, respect and trust in communication. It might also indicate the existing social categorization of professions with an unequal distribution of power in ECI teams which manifests in the fear of ridicule and lack of trust in discussion (Mitchell et al., 2010). Striving for personal (not professional) cohesiveness reduces threats to identity, but also has a potential to refocus the attention - from the task to the personal relationships (ibid.) which is one of the findings of our research.

In the category of the team competence (Figure 3) the dominant (expected as well as valued in practice) competence is the ability to express one's opinion. This preference can have two implications: on the one hand, it can indicate the professionals' need to learn from each other, on the other - the effort to protect and strengthen one's professional status and the body of professional knowledge. The analysis of training portfolios (see Figure 1) reveals that there are significant discrepancies in such knowledge fields as in the assessment of a child's needs and problems, child development and collaboration with families, etc. Such cognitive heterogeneity in interprofessional groups can lead to misunderstandings, affective conflict and defensive behavior (Mitchell et al., 2010). Bourdieu speaks of the power of an institution (in our case represented by a particular professional) not only to communicate what the other's identity is, but to impose it on the other informing "in authoritarian manner what he is and what he must be" (Bourdieu, 1991, p. 121, in McKnight) and also, "to discourage any attempt to cross the line, or to transgress..." (Bourdieu, 1991, p. 336). As Frank states, "humans do compete for capital and, often in the same activity, they work to achieve mutual understandings and excellence in particular practices for their inherent value"... (p. 325).

According to Anderson et al. (2010), Mitchell et al. (2010), professionals from different fields operate distinct knowledge that is embedded in the language the profession uses. Professional language, a kind of linguistic capital, symbolizes access to professional power and creates a particular discourse which helps to reproduce a particular practice or habitus. As knowledge is transferred through expressive language it explains the high value respondents in our research allocated to the expression of one's opinion. A monopoly of knowledge may become a barrier when professionals "fail to openly consider information or perspective that threatens their dominant paradigms" (Mitchell et al., 2010, p. 14). It is evident (Figure 1) that there are gaps as well as overlaps in competencies developed within the framework of different professions. 
Therefore, sharing of knowledge across professional boundaries is essential in order to cooperate effectively (Anderson et al., 2010). The sharing of meanings and terms also indicates the emergence of a common narrative, which is so important for the development of an inter-professional collaboration culture. However, in the inter-professional team not only the knowledge sharing, but similar problem solving strategies and mutual support are important that the collaboration could be called inter-professional (Olenick et al., 2010). In our research these competencies were not yet evidenced, and little observed in practice.

Figure 1 suggests that in some knowledge and practice areas the bridges have yet to be created to connect possibly different mental paradigms. For instance, one of the first aims of early childhood intervention is to conduct the assessment of the child's and his / her family strengths and needs. According to the first research data, most competent in this area are psychologists $(76 \%)$, least - social field professionals (10\%). Such an imbalance contradicts the principles of an ecological model of assessment and generates doubts as to whether services provided by early childhood intervention teams can be familycentred. In relation to Bourdieu's habitus, free sharing of knowledge and, especially, values and approaches is necessary for the "conversion" of professional dispositions embedded in professional cultures. However we haven't found any intention which reveals an active disposition to involve others into one's professional field, such as teaching each other's discipline-based knowledge and values (Clark et al., 2007).

The competence "ability to solve problem" appeared only in the practice reflection (respondents observed this skill, but did not formulate it in speculative thinking). On the contrary, "ability to coordinate actions" appears only in the speculative thinking. The emergence of the competence that the participants did not think a priori indicates that in real practice situations specialists of ECI teams do encounter difficulties which require a common solution. However, as Mitchel et al. (2010) warn, problem solving may be both innovative in interprofessional groups, but also difficult due to semantic misunderstandings which imply the need for an inter-professional narrative and, it might be added - the "conversion" of established habitus.

In the general overview of competencies there is an evident lack of attention to the ones which were grouped under the category "collaboration with parents". This result is partly explained through the analysis of training portfolios (Figure 1) where the knowledge difference between health care professionals (35\% had an opportunity to acquire these skills) and, for instance, psychologists (61\%) is evident. The "invisibility" of parents in the respondents' propositions is even more interesting due to the fact that parents having children with disabilities were invited to some seminars in order to create an opportunity for ECI team members to analyse and give voice to the family situation.In this respect, the neglect of the family - which should be the main focus of an ECI 
team applying the ecosystem model - generates doubts as to whether the researched teams can be described as inter-professional.

According to the concept analysis, made by Olenick et al. (2010), one of the important features of the inter-professional team is its cohesive work focusing on the service user or how it is "apprehended as co-created at the interface between the service user and the various professionals" (D'Amour and Oandasan, 2005, in Kvärnstrom et al., 2012, p. 288). In our case, specialists of EIC were more focused on each other's competence which suggests another term for the current state of early childhood intervention in Lithuania: it seems more inter-disciplinary than inter-professional. Bourdieu's term "misrecognition" might be applied here, which implies that in the labyrinth of different professional languages, moderated by the new meanings attached to familiar words, it is too challenging to see parents as partners of the team when much has yet to be learned from each of other (from colleagues, representing different, yet related fields of knowledge). Moreover, the efforts might be put into a reconstruction of professional power relations, mentioned earlier. However, as Anderson et al. (2010) state, "working together through learning from service user insights and experience has proved to be a powerful common currency" (p. 238).

\section{Conclusion and implications for ECI practice}

In summary, the training content of professionals, represented in different early childhood intervention discipline fields, reveals discrepancies in some competence areas. In the daily inter-professional encounter this creates a need for constant discourse amongst professionals, sharing of power and "conversion" of traditional professional habitus, in general. In the context of the interchange processes that emerge in inter-professional discourse there is a danger of neglecting the important partners - families of children at risk. In order for inter-professional collaboration in early childhood intervention to be successful, parents' voice - in terms of expertise and language - must also be included in the discussion.

The present study has some limitations. Firstly, the participants were chosen using convenience sampling, and the findings of this exploratory research cannot be generalized to the overall situation in the country. Secondly, the findings are based on opinions of professionals representing different professional fields, but no family member took part in the questionnaire. Thirdly, the represented ECI teams were too diverse according to the profession and to the number of representatives. Finally, the questionnaires were delivered to the participants only at the final stage of the seminar, not before it; therefore any advantages occurring from the training could not be identified.

Given the limitations of the current study, a clear future direction is to go on with similar research in other ECI teams focusing on indicators of both 
professional and inter-professional support. Family members should be included in all phases of action research in order to gain a family's perception of early childhood intervention teams' services and find out what competencies parents observe and which they perceive as most valuable. The questionnaire should be delivered before the seminar and at the end of the seminar, and the participants should be acquainted with the research results in order to help practitioners to recognize the discrepancies between the desired and current practice.

\section{References}

Ališauskienè, S. (2005). Ankstyvoji intervencija vaikystëje. Monografija. Šiaulių universiteto leidykla.

Ališauskienė, S., Mikalajūnienè, J., Čegytė, D. (2007). Ecological Approach in Meeting Special Needs of Early Age and Pre-School Children. Special Education, 2(17), 107119.

Ališauskienè, S. (2010). Early Childhood Intervention in Lithuania: Organisation and Challenges. In Pretis, M. (Ed.). Early Childhood Intervention Across Europe. Towards Standards, Shared Resources and National Challenges (pp. 65-82). Maya Akademi Yayın Dağıtım Eğitim Danışmanlık. Retrieved from http://www. mayakademi. net

Anderson, E.S., Smith, R., Thorpe, L.N. (2010). Learning from lives together: medical and social work students' experiences of learning from people with disabilities in the community. Health and Social Care in the Community, 18(3), 229-240.

Armatzaki, M, Kypriotaki, M., Voreadou, C., Dardioti, A., Stathi, I. (2013). Communities of practice and participatory action research: the formation of a synergy for the development of museum programmes for early childhood. Educational Action Research, 21 (1), 4-27.

Block, A.W., Block, S. R. (2002). Strengthening social work approaches through advancing knowledge of early childhood intervention. Child and Adolescent social work journal, 19 (3), 191-208.

Bossche, P. V., Gijselaers, W. H., Segers, M., Kirschner, P. A. (2006). Social and Cognitive Factors Driving Teamwork in Collaborative Learning Environments: Team Learning Beliefs and Behaviours. Small Group Research, 37, 490-521.

Bourdieu, P. (1977). Outline of a theory of practice. Cambridge university press.

Carpenter, B., Phil, M. (1997). Empowering parents: the use of the parent as researcher paradigm in early intervention. Journal of child and family studies, 6(4), 391-398.

Clark Ph., Cott Ch., Drinka Th. (2007).Theory and practice in interprofessional ethics: a framework for understanding ethical issues in health care teams. Journal of interprofessional care, 21(6), 591-603.

Elo, S., Kyngäs, H. (2007). The qualitative content analysis process. Journal of advanced nursing, 62(1), 107-115.

Frank, A.W. (2012). Bourdier. The Master. Canadian journal of Sociology, 37(3),319-330.

Freeman, R., Vakil, Sh. (2004). The role of family childcare providers in early intervention. Early childhood education journal, 32 (2), 121-125.

Guralnick, M. (2001). A Developmental Systems' Model for Early Intervention. Infant and Young Children, (4) 2,.1-18. International Society on Early Intervention (ISEI): Aspen Publishers, Lippincott Williams \& Wilkins.

Happo, I., Maata, K., Uusiautti, S. (2012). How do early childhood education teachers perceive their expertise? A qualitative study of child care providers in Lapland, Finland. Early childhood education. July 2013, Volume 41, Issue 4, pp 273-281. 


\section{SOCIETY. INTEGRATION. EDUCATION. Volume III}

Inkilä, J., Flinck, A. Luukkaala, T., Åstedt-Kurki, P., Paavilainen E. (2013). Interprofessional Collaboration in the Detection of and Early Intervention in Child Maltreatment: Employees' Experiences. Nursing Research and Practice. Volume 2013, 10 p.

King, A. (2000). Thinking with Bourdieu against Bourdieu: A 'Practical' Critique of the Habitus. Sociological Theory, 18 (3), 417-433.

Kvärnstrom, S., Hedberg, B., Cedersund, E. (2012). The dual faces of service user participation: implications for empowerment professes in interprofessional practice. Journal of Social work, 13(3), 287-307.

Lave, J., \& Wenger, E. (1998). Communities of Practice: Learning, Meaning, and Identity. Cambridge University Press.

McKnight, D., Chandler, P. (2012). The complicated conversation of Class and Race in Social and Curricular Analysis: An examination of Pierre Bourdieu's interpretative framework in relation to race. Educational Philosophy and theory, 44, (S1), 74-95.

McNiff, J. (2010). Action research for professional development: Concise advice for new and experienced action researchers. Dorset: September books.

Mitchell, R., Parker, V., Giles, M., White, N. (2010). Toward realizing the potential of difersity in composition of interprofessional health care teams. An examination of the cognitive and psychosocial dynamics of interprofessional collaboration. Medical Care Research and Review, 67 (1), 3-26.

Olenick, M., Allen, L., R., Smego, R.A. (2010). Interprofessional education: a concept analysis. Advances in Medical Education and Practice, 1, 75-84.

Payler, J. K., Georgeson, J. (2013). Personal action potency: early years practitioners participating in interprofessional practice in early years settings. International Journal of Early Years Education, 21, 39-55.

Peterander, F. (2003 a). La formation du personnel à l'intervention précoce en milieu familial en Allemagne: de nouvelles compétences pour une nouvelle profession. La revue internationale de l'intervention familiale, 7 (1), 81-90.

Peterander, F. (2003 b). Supporting the Early Intervention Team. In: Samuel L. Odom, Marci J. Hanson, James A. Blackman, S. Kaul. Early Intervention Practices around the World. (pp. 301-331). Brookes Publishing.

Pizur-Barnekow, K., Rhyner, P. M., Doering, J., Patrick, T. (2011). An Interdisciplinary Approach to Health Literacy for Education, Research, and Practice in Early Childhood Intervention. Perspectives on Language Learning and Education, 18, 62-67.

Reeves, S., Zwarenstein, M., Goldman, J., Bar, H., Freeth, D., Koppel, I., Hammick, M. (2010). The effectiveness of interprofessional education: Key findings from a new systematic review. Journal of interprofessional care, 24(3), 230-241.

Sargeant, J., Loney, E., Murphy, G. (2008). Effective interprofessional teams: "Contact is not enough" to build a team. Journal of continuing education in the health professions, 28(4), 228-234.

Shimoni, R., Ferguson, B. (1992). Rethinking parent involvement in child care programs. Child \& Youth Care Forum, 21 (2), 105-118.

Thompson, K. (2013). Multi-agency information practices in children's services: the metaphorical "jigsaw" and professionals' quest for a "full" picture. Child and family social work, 18 (2), 189-197.

Watkin, A., Lindqvist, S., Black, J., Watts, F. (2009). Report on the implementation and evaluation of an interprofessional learning programme for inter-agency child protection teams. Child abuse review, 18, 151-167.

Wright, D., Brajtman, S. (2011). Relational and embodied knowing: nursing ethics withing the interprofessional team. Nursing Ethics, 18(1), 20-30. 